\title{
Jane Johnson and Anne Van Rensselaer (eds): Siblings: The Autism Spectrum Through Our Eyes
}

\author{
Jessica Kingsley Publishers, London, 2010, 94 pp, ISBN 978-1-84905-829-2, \\ $\$ 12.95$ (paper)
}

Lorna Timmerman

Published online: 17 September 2011

(C) Springer Science+Business Media, LLC 2011

There is much written about individuals on the autism spectrum but relatively little about the siblings of children with autism. Growing up with a sibling on the spectrum can be difficult at best. Embarrassment, constant annoyance and lack of attention may be daily occurrences for the siblings of children with autism, but this book highlights that there are also many positive qualities of having a sibling with autism.

To combat this underrepresentation of the sibling perspective and to illuminate the fact that siblings of autism are not alone, Siblings: The Autism Spectrum Through Our Eyes was written to focus on the equally rewarding aspects of having a sibling on the spectrum. The book begins with a brief preface that acknowledges that although there are many support groups for siblings of children on the spectrum, not everyone has access to such a group. This book was written to help these siblings feel less alone and to read about others' viewpoints and encounters with having a sibling on the spectrum. The book is then divided into two parts, beginning with a 13-chapter section for Younger Children and Parents. The second part (six chapters) is geared towards Teenagers and Parents. Chapter 17 is a poem while the rest of the chapters in the book are narratives.
Each chapter is written by a sibling of a person on the autism spectrum. The age of each chapter's author is provided to give reference to the chapter. Ages of authors range from 9 to 41 , with siblings of similar ages. Some sibling authors are in the throes of dealing with daily tantrums and issues while other sibling authors have moved away and are living independently from their sibling with autism. Many different occurrences, incidents and perspectives are offered throughout the book, which allows most every reader to relate to some author's experiences.

Siblings: The Autism Spectrum Through Our Eyes should be read by all persons desiring a better understanding of the issues that siblings of children with autism experience. This book is a good read for parents and young adult siblings of children with autism. It offers wisdom of those who have gone before to those now dealing with the issues of having a sibling with autism. It is a concise, 94-page book that will help readers truly understand and appreciate those on the spectrum and how their brothers and sisters perceive their both positive and not-so-positive experiences of having a sibling on the autism spectrum.

L. Timmerman $(\bowtie)$

Ball State University, 2000 University Ave, Muncie, IN 47306,

USA

e-mail: 1ctimmerman@bsu.edu 